San Jose State University

From the SelectedWorks of Marjorie R. Freedman

May, 2011

\title{
Point-of-Purchase Nutrition Information Influences Food-Purchasing Behaviors of College Students: A Pilot Study
}

Marjorie R. Freedman, San Jose State University

Rachel Conners, San Jose State University 
Title: Point-of-Purchase Nutrition Information Influences Food-Purchasing Behaviors of College Students: A Pilot Study

\title{
Journal of the American Dietetic Association
}

Key words: Point of Purchase, University, Shelf tags

\section{Author information:}

Corresponding author:

Marjorie R. Freedman, PhD

Assistant Professor, Department of Nutrition, Food Science \& Packaging

Rachel Connors, MS

Department of Nutrition, Food Science \& Packaging

San Jose State University

\begin{abstract}
The goal of point-of-purchase (POP) nutrition information is to help consumers make informed, healthful choices. Despite limited evaluation, these population-based approaches are being advocated to replace traditional, more expensive, individual behavior change strategies. Few studies have examined the effect of POP information on buying patterns of college students, a group with high obesity rates and poor eating habits. This quasi-experimental pilot project sought to determine whether the "Eat Smart" POP program affected food-purchasing habits of multi-ethnic college students shopping at an on-campus convenience store. Baseline sales data of foods in the cereal, soup, cracker and bread categories were collected for six weeks during Fall 2008. After winter break, a few food items within each of these food categories were labeled as healthful using a "Fuel Your Life" shelf tag, and sales data were then collected for five weeks. In each of the four food categories, non-tagged foods were available at the identical price as tagged items. Following intervention, there were increased sales of tagged items (measured as a percentage of total sales) in the cereal, soup, and cracker categories, while sales of bread decreased. Although none of these changes were statistically significant, the intervention resulted in a $3.6 \pm 1.6 \%(\mathrm{P}=.082)$ increase in the percentage of sales from tagged items. Thus, providing POP nutrition information in a college campus convenience store may promote healthful food choices. A longer study examining the effect of POP on sales of items in other food categories is warranted.
\end{abstract}

\section{INTRODUCTION}

Poor diet and physical inactivity leading to obesity is poised to overtake tobacco use as the leading cause of preventable death in the United States (1). Currently, over $30 \%$ of adult Americans are obese (2), increasing their risk for cardiovascular disease, hypertension, type 2 diabetes, and several forms of cancer (3). Weight gain is primarily caused by an energy imbalance, the result of too many calories consumed relative to those expended (4). On the energy intake side, diet and eating behaviors are influenced by a complex set of interactions, ranging from individual choice to broader social, cultural, economic and environmental 
determinants (5). Strategies for changing nutrition behavior focusing on the individual (i.e., downstream approaches) have high costs relative to their efficacy and reach (6). This has led to increasing interest in developing policies and environments that support healthful eating and obesity prevention in a given population rather than for individuals (i.e., upstream approaches) (7-9). Policy approaches can affect health behaviors and alter physical environments in an entire population (10). Environmental approaches to healthful eating include improving access to and availability of healthful foods and providing point-of-purchase (POP) nutrition information (11),

Because POP nutrition information has the potential to influence healthful eating patterns in entire populations (11), there is increasing interest in legislating the provision of POP information (12). Studies examining the effect of POP information on food purchasing behaviors in grocery stores, restaurants, universities, and the workplace have recently been reviewed $(11,13)$. In grocery stores, of the ten interventions that focused primarily on information strategies (14-23), six of the studies showed increased sales for, at most, $50 \%$ of the targeted food items (17-22).

Currently, four different shelf-tag POP initiatives are being used in grocery stores in the United States (24-27). The Guiding Stars ${ }^{\circledR}$ program (promoted in Hannaford stores in the Northeast) assigns one to three stars to various food items, to identify foods with higher nutritional value (24). The $\mathrm{NuVal}^{\mathrm{TM}}$ Nutritional Scoring System (found in stores throughout the Northeast and Midwest), factors over 30 nutrients into an algorithm to compute a single nutrition "score" (from 1 to 100) for each food item, assigning higher scores to foods and beverages with higher nutrient content (25). Nutrition IQ shelf tags (used in Acme, Cub and Albertsons stores) comprise color-coded tags displaying nutrition content for sodium, fiber, saturated fat, calcium, protein, whole grains and calories (26). The Healthy Ideas program (found in Stop\&Shop stores throughout the Northeast) assigns a "healthy ideas "TM " logo to over 3000 items, all of which have at least $10 \%$ of the daily recommended amount of one nutrient (27). Though the foregoing POP shelf-tag programs are widely distributed in grocery stores throughout the country (24-27), peerreviewed studies on their efficacy are lacking.

In the university setting, provision of POP nutrition information in cafeterias (28-33) and vending machines (34-36) has been studied. No research has examined the effect of POP information provided to students shopping at on-campus convenience stores. Notably, $25 \%$ of college students are obese (37), few meet the Dietary Guidelines for Americans (38-41), and many are developing dietary habits that influence later health risk (42). Consequently, it is important to determine whether information provided to college students in this venue influences their food purchasing habits. The objective of this pilot project was to examine the effect of a POP nutrition program on the food-buying habits of multi-ethnic students who shopped at an oncampus convenience store at a large urban university. The hypothesis was that more students would purchase healthful food items, promoted as part of the "Eat Smart" campaign and tagged with the "Fuel Your Life" logo, compared to identically-priced, non-tagged items within the same food category.

\section{Study Venue}

\section{METHODS}

The "Eat Smart" POP nutrition information program was conducted in an on-campus convenience store, Village Market (VM), located at an urban university with no ethnic majority (23\% Asian, 16\% Hispanic, 29\% White, and 32\% listed in other ethnic groups). VM is on the 
ground floor of a three-unit high-rise residential complex called Campus Village, which houses about 2,000 students, and VM is also very close to two other campus residential units (The Classics) which house an additional 1,300 students. The purchase of a university meal plan is mandatory for the approximately 1,900 freshman and lower division students living in The Classics and Campus Village, but the meal plan is optional for 1,400 upper division students living in Campus Village who have apartments with full kitchens. Although anyone can shop at VM, its primary customers are students who live on campus. Food items available for purchase at VM include staples (e.g., bread, cereal, luncheon meats, frozen meals, fruits); snacks (e.g., chips, nuts, candy, energy bars, crackers); beverages (e.g., water, milk, soft drinks, juice, energy drinks); and made-to-order coffee and sandwiches. VM is open from 7 AM to 1 AM Monday through Friday, and from 10 AM to 1 AM on weekends. Since outcome measures were based on sales data, the San Jose State Institutional Research Board for human subjects categorized this research as exempt.

\section{Study Design and the "Eat Smart" Intervention}

This 11-week quasi-experimental study collected baseline sales data for 6 weeks during the middle of the Fall 2008 semester. These 6 weeks were chosen to allow students to establish baseline food-purchasing habits after starting the school year. Then, after students returned from Winter break, "Eat Smart" program materials were placed in VM. Sales data were collected during the middle of the Spring 2009 semester for 5 weeks, ending just before students left for Spring break.

The intervention included 1.25"x 3" shelf display tags (Daydots Zippy Tags, \#11206-0100) featuring the "Fuel Your Life" logo (Figure), snapped onto shelves directly beneath the tagged food item. Tags were checked daily and repositioned or replaced as needed. An "Eat Smart" promotional poster was placed in the front window of VM, and brochures describing the "Eat Smart" program were placed next to the only cash register. These posters and brochures aimed to educate students to "Eat Smart, Feel Smart and Be Smart," by directing them to purchase food items with the "Fuel Your Life" shelf tags throughout the store.

Figure "Fuel Your Life" logo found on shelf tags, used to identify healthy foods in the "Eat Smart" campaign.

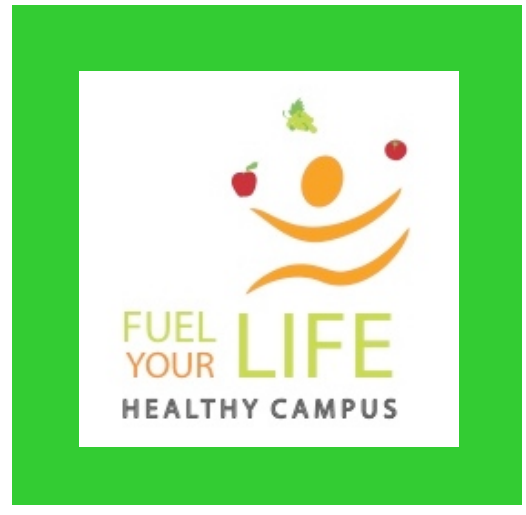


Although there are many different categories of food available for purchase at VM, healthful items in only seven food categories (cereal, bread, soup, cracker, canned vegetable, granola/energy bar, and salad dressing) were tagged throughout the market. Within each of these seven categories, the healthful tagged items were chosen based on somewhat arbitrary criteria since the goal of the study was to determine whether the presence of a POP shelf tag would increase sales of a given food item, and not whether the nutritional quality (which could be determined by reading the Nutrition Facts panel) impacted the food item's sales. Data analysis was limited to items in the cereal, soup, cracker and bread categories, since these frequently purchased items had identical pricing throughout the category. By analyzing sales data only for food items having identical pricing throughout a category, selection bias associated with cost was eliminated. In the cereal category, tagged items all had $\geq 3$ grams of fiber and $\leq 5$ grams of fat per serving. In the soup category, soups with $\leq 5$ grams of fat per serving were tagged. Tagged items in the cracker and bread categories were Reduced Fat Wheat Thins ${ }^{\circledR}$ (and not original Wheat Thins ${ }^{\circledast}$, Ritz $^{\circledast}$, Triscuit ${ }^{\oplus}$, and Cheez-It ${ }^{\circledR}$ crackers), and $100 \%$ whole wheat bread (and not white bread). These criteria resulted in applying shelf tags to seven soups, five cereals, one cracker and three breads, whereas 15 soups, 15 cereals, four crackers and one bread were left untagged during the intervention period.

\section{Statistical Analysis of Sales Data}

All sales data came from a computerized cash-register system. Two separate analyses were conducted. First, sales of individual tagged items during the baseline period were compared to sales of the same items during the intervention period. Second, tagged items as a percentage of total items sold in each category were calculated, and sales were compared for the two time periods. Data were assessed for normality by examining skewness and kurtosis. The Mann-Whitney $U$-test for non-normally distributed data was conducted using SPSS for MAC (version 16.0, 2008, SPSS Inc., Chicago IL) to determine significant differences between periods. Results are presented as means \pm standard deviations (SD) and statistical significance was set as $\mathrm{P}<0.05$.

\section{RESULTS AND DISCUSSION}

There was no significant difference in sales of any food item between baseline and intervention. However, overall sales of tagged items, as a percentage of total sales in the cereal, soup, and cracker categories, increased as a result of the intervention, while sales of tagged bread items decreased (Table 1). Though not statistically significant $(\mathrm{P}=.082)$, the intervention resulted in a $3.6 \%$ increase in the percentage of sales from tagged items. 
Table 1. Sales of Tagged Items as a Percent of Total Sales in Each Category ${ }^{\text {a }}$

\begin{tabular}{|l|c|c|r|r|r|}
\hline Category & Baseline & Intervention & Difference $^{\mathrm{b}}$ & $\mathrm{Z}$ score & P value $^{\mathrm{c}}$ \\
\hline Cereal & $15.3 \pm 3.1$ & $18.8 \pm 4.4$ & $3.5 \pm 2.3$ & 1.287 & .247 \\
\hline Soup & $22.3 \pm 2.5$ & $24.6 \pm 3.2$ & $2.3 \pm 1.7$ & 1.011 & .329 \\
\hline Crackers & $21.2 \pm 1.8$ & $30.0 \pm 1.0$ & $8.8 \pm 4.2$ & 1.654 & .126 \\
\hline Bread & $57.3 \pm 2.1$ & $55.6 \pm 2.3$ & $-1.7 \pm 9.7$ & .274 & .792 \\
\hline All items & $24.2 \pm 2.0$ & $27.8 \pm 3.5$ & $3.6 \pm 1.6$ & 1.851 & .082 \\
\hline
\end{tabular}

${ }^{a}$ Data presented as means \pm standard deviations.

${ }^{\mathrm{b}}$ Difference represents the change in percentage of sales between the intervention and baseline periods.

${ }^{\mathrm{c}}$ Analysis to determine significance between intervention and baseline periods performed using Mann Whitney $U$-test for non-normally distributed data; exact significance not corrected for ties.

This research supports previously published POP nutrition information strategies that successfully impacted food-purchasing behaviors in grocery stores (17-22). Three of these studies were conducted in large urban grocery stores $(17,20,22)$. Levy et al. (17) reported significantly increased sales of eight low- or reduced-calorie, -fat, -cholesterol, or -sodium items following a POP intervention (shelf labels attached to price tags and a "Special Dietary Alert" pamphlet explaining the program). In a 2-year study using shelf labels that identified recommended foods, Schucker et al. (22) reported increased sales of eight out of 16 items, including crackers and canned soup. Employing their "Eat for Health" program, Rodgers et al. (20) used signs and shelf labels with the word "recommended" on them, along with an explanatory guide at checkout stands, to increase sales of high-fiber and low-fat items. Using computerized sales data to assess program efficacy, Rodgers et al. reported that sales of recommended high-fiber vegetables increased significantly during the 2-year intervention period. Muller (18) reported increased sales of nutrient-dense foods resulting from a POP intervention that used signs suspended above aisles, and shelf tags pointing to signs, despite the limitation of a very short, 2-week intervention. Närhinen and Nissinen (19) grouped healthier foods together on shelves under a sign reading "The Healthier Choice," and used computerized sales data to report a 37 to $49 \%$ increase in the purchase of low-sodium and/or low-saturated fat packaged foods. However, they also noted that sales of targeted items decreased during periods when competing items were promoted through coupons or sales. Finally, using a "Nutrition Quotient" star rating system displayed on posters and take-home replicas, Russo et al. (21) attempted to increase sales of healthful items in six product categories, but showed only significantly increased sales for targeted low-sugar cereals and decreased sales of high-sugar cereals.

The current study's results also support the preliminary results of the Hannaford Supermarkets' Guiding Stars ${ }^{\circ}$ program, which showed a 4\% decline in sales of whole milk (which received no stars) compared to a $1 \%$ increase in sales of fat-free milk (which received three stars), and showed a 5\% decrease in sales of ground beef (which received no stars) 
compared to a $7 \%$ increase in sales of ground beef with higher star ratings (Lisa Sutherland, personal communication, July 9, 2009).

Several studies indicate that purchases increase following price reductions of healthful food in vending machines $(43,44)$, cafeterias $(30,45,46)$, and restaurants $(47)$. In the current study, the price of healthful tagged items was the same as untagged items within each food category, thereby eliminating the confounding variable of price from food-purchasing behavior. Recent reviews of POP information programs cite problems with methodology, study duration, and assessment tools, and call for inclusion of behavioral outcomes such as food purchase behaviors, implementation in realistic settings, and examination of diverse populations $(11,13)$. The "Eat Smart" program employed in the current study addresses these concerns by using computerized sales data to assess purchasing behavior, and by examining actual consumer behavior in a multi-ethnic student population.

Despite these strengths, the greatest limitation of this pilot project was its short duration. Although computerized sales data were available for the entire semester, sales data were provided to researchers for two similar time periods during the Fall and Spring semesters for selected items. Second, daily monitoring during the intervention period revealed tagged items were often sold out, likely because of increased demand and ordering based on previous, historical (baseline) buying patterns. This decreased availability could have impacted buying patterns. Third, the last week of the intervention period coincided with the week before Spring break, a time when most students leave town, and would not be expected to make grocery purchases. Thus, low sales during this week may have negatively impacted results. Finally, no feasible means could be devised to examine consumer behavior at the level of the individual (as opposed to the population). Changes in individuals' behavior due to POP information can thus only be assumed, but not proven, since it is unknown whether individuals who purchased items during baseline were the same as those who purchased items during intervention.

\section{CONCLUSIONS}

This pilot project was the first to use computerized sales data to examine the effect of a POP nutrition information program on the food-buying habits of multi-ethnic college students. Promising (albeit, not statistically significant) results imply that students were influenced by "Fuel Your Life" shelf tags and related materials. Despite several study limitations, the program was successful in increasing the percentage of tagged food items sold relative to other nontagged items in the same category. Keeping all items in the same category at the same price meant that consumer choice was based on perceived nutritional benefit, not economics. Future studies should collect data for a longer period of time, and should examine purchasing choices of other types and kinds of foods. Such studies are necessary to lend scientific support to public health policies promoting POP nutrition information.

\section{ACKNOWLEDGEMENTS}

This research was supported by a Kaiser Permanente Northern California HEAL grant. We would like to thank Ryan Ptucha and Gabrielle Ortega at Village Market for their help. 


\section{REFERENCES}

1. Mokdad A, Marks, JS, Stroup, DF, Gerberding, JL. Actual causes of death in the United States, 2000. JAMA. 2004;291:1238-1245.

2. Ogden CL, Carroll MD, Curtin LR, McDowell MA, Tabak CJ, Flegal KM. Prevalence of overweight and obesity in the United States, 1999-2004. JAMA. 2006;295:1549-1555.

3. Pi-Sunyer FX. Medical hazards of obesity. Ann Intern Med. 1993;119:655-660.

4. WHO. Obesity: Preventing and Managing the Global Epidemic: Report of a WHO Consultation. WHO Technical Report Series; 894. Geneva: The Office of Publication, World Health Organization, 1999;1-253.

5. Contento I. An overview of food choice and dietary change: Implication for nutrition education. Nutrition Education: Linking Research, Theory, and Practice. Boston, MA: Jones and Bartlett; 2007.

6. Ammerman AS, Lindquist $\mathrm{CH}$, Lohr KN, Hersey J. The efficacy of behavioral interventions to modify dietary fat and fruit and vegetable intake: A review of the evidence. Prev Med. 2002;35:25-41.

7. Orleans CT. Promoting the maintenance of health behavior change: recommendations for the next generation of research and practice. Health Psychol. 2000;19(suppl 1):S76-83.

8. Dorfman L, Wallack L. Moving nutrition upstream: the case for reframing obesity. $J$ Nutr Educ Behav. 2007;39(suppl 2):S45-50.

9. Berman M, Lavizzo-Mourey, R. Obesity prevention in the information age. Caloric information at the point of purchase. JAMA. 2008;300:433-435.

10. Sallis JFO, Owen, N. Ecological models of health behavior. In: Glanz K, Rimer, BK, Lewis, FM, eds. Health Behavior and Health Education. San Francisco, CA: Jossey-Bass; 2002:462-484.

11. Seymour JD, Yaroch AL, Serdula M, Blanck HM, Khan LK. Impact of nutrition environmental interventions on point-of-purchase behavior in adults: A review. Prev Med. 2004;39(suppl 2):S108-136.

12. Nutrition Labeling in Chain Restaurants: State and Local Bills/Regulations 2009-2010. Center for Science in the Public Interest Website. http://cspinet.org/new/pdf/ml_bill_summaries_09.pdf. Accessed July 5, 2009.

13. Harnack LJ, French SA. Effect of point-of-purchase calorie labeling on restaurant and cafeteria food choices: A review of the literature. Int J Behav Nutr Phys Act. 2008;5:51-56.

14. Achabal DD, McIntyre SH, Bell CH, Tucker N. The effect of nutrition P-O-P signs on consumer attitudes and behavior. J Retail. 1987;63:9-24.

15. Ernst N, Wu M, Frommer P, Katz E, Matthews O, Moskowitz J, Pinsky JL, Pohl S, Schreiber GB. Education at the point of purchase: The Foods for Health project evaluated. Prev Med. 1986;15:60-73.

16. Jeffery RW, Pirie PL, Rosenthal BS, Gerber MW, Murray DM. Nutrition education in supermarkets: an unsuccessful attempt to influence knowledge and product sales. J Behav Med. 1982;5:189-200.

17. Levy AS, Schucker RE, Tennery JE, Mathews O. The impact of a nutrition information program on food purchases. J Public Polict Mak. 1985;4:1-16.

18. Muller T. The use of nutritive composition data at the point of purchase. J Nutr Educ. 1984;16:422-425.

19. Närhinen M, Nissinen A, Puska, P. Changes in supermarket sales during and after a staged health promotion program. Brit Food J. 2000;102:308-329. 
20. Rodgers AB, Kessler LG, Portnoy B, Potosky AL, Patterson B, Tenney J, Thompson FE, Krebs-Smith SM, Breen N, Mathews O, Kahle, LL. Eat for Health: A supermarket intervention for nutrition and cancer risk reduction. Am J Public Health. 1994;84:72-76.

21. Russo JE, Staelin R, Nolan CA, Russel GJ, Metcalf BL. Nutrition information in the supermarket. J Cons Research. 1986;13:48-69.

22. Schucker RE, Levy AS, Tenney JE, Mathews O. Nutrition shelf-labeling and consumer purchase behavior. J Nutr Educ. 1992;24:75-81.

23. Soriano E, Dozier DM. Selling nutrition and heart-healthy behavior at the point-of-purchase. J Appl Nutr. 1978;30:56-65.

24. Hannaford Guiding Stars ${ }^{\star}$. Hannaford Guiding Stars Website. http://www.hannaford.com/ Contents/Healthy_Living/Guiding_Stars/index.shtml. Accessed July 1, 2009.

25. $\mathrm{NuVal}^{\mathrm{TM}}$ Nutritional Scoring System. $\mathrm{NuVal}^{\mathrm{TM}}$ Nutritional Scoring System Website. http://www.nuval.com. Accessed July 1, 2009.

26. Nutrition iQ Website. http://www nutritioniq.com/home.do. Accessed November 4, 2009.

27. Stop\&Shop Healthy Ideas ${ }^{\mathrm{TM}}$ Website. http://www.stopandshop.com/living_well/ healthy_living.htm. Accessed November 4, 2009.

28. Aaron J Evans R, Mela D. Paradoxical effect of a nutrition labeling scheme in a student cafeteria. Nutr Res. 1995;15:1251-1261.

29. Buscher LA, Martin KA, Crocker S. Point-of-purchase messages framed in terms of cost, convenience, taste, and energy improve healthful snack selection in a college foodservice setting. J Am Diet Assoc. 2001;101:909-913.

30. Cinciripini P. Changing food selections in a public cafeteria: An applied behavior analysis. Behav Modif. 1984;8:520-539.

31. Davis D, Rogers T. Point-of-choice nutrition information for the modification of milk selection. J Am Coll Health. 1982;30:275-278.

32. Davis-Chervin D, Rogers T, Clark M. Influencing food selection with point-of-nutrition information. J Nutr Educ. 1985;17:18-22.

33. Liddell JA, Lockie GM, Wise A. Effects of a nutrition education programme on the dietary habits of a population of students and staff at a center for higher education. J Hum Nutr Diet. 1992;5:23-33.

34. French S.A. Pricing effects on food choices. J Nutr. 2003;133:841S-843S.

35. Hoerr SM, Louden VA. Can nutrition information increase sales of healthful vended snacks? J Sch Health. 1993;63:386-390.

36. Larson-Brown L. Point-of-purchase information on vended foods. J Nutr Educ. 1978;10:116118.

37. The American College Health Association. American College Health Association-National College Health Assessment Spring 2008 Reference Group Data Report (Abridged). J Am Coll Health. 2009;57:477-488.

38. Racette SB, Deusinger SS, Strube MJ, Highstein GR, Deusinger RH. Weight changes, exercise, and dietary patterns during freshman and sophomore years of college. J Am Coll Health. 2005;53:235-251.

39. Anding J, Suminski RR, Boss L. Dietary intake, body mass index, exercise, and alcohol: Are college women following the Dietary Guidelines for Americans? J Am Coll Health. 2001;49:167-171.

40. Brown LB, Dresen RK, Eggett DL. College students can benefit by participating in a prepaid meal plan. J Am Diet Assoc. 2005;105:445-448. 
41. Kolodinsky J, Harvey-Berino JR, Berlin L, Johnson RK, Reynolds TW. Knowledge of current dietary guidelines and food choice by college students: Better eaters have higher knowledge of dietary guidance. J Am Diet Assoc. 2007;107:1409-1413.

42. Youth Risk Behavior Surveillance: National College Health Risk Behavior Survey-United States, 1995. http://www.cdc.gov/mmwr/preview/mmwrhtml/

00049859.htm. Accessed July 1, 2009.

43. French SA, Jeffery RW, Story M, Breitlow KK, Baxter JS, Hannan P, Snyder MP. Pricing and promotion effects on low-fat vending snack purchases: the CHIPS Study. Am J Public Health. 2001;91:112-117.

44. French SA, Jeffery RW, Story M, Hannen P, Snyder MP. A pricing strategy to promote lowfat snack choices through vending machines. Am J Pub Health. 1997;87:849-851.

45. French SA, Story M, Jeffery RW, Snyder P, Eisenberg M, Sidebottom A, Murray D. Pricing strategy to promote fruit and vegetable purchase in high school cafeterias. J Am Diet Assoc. 1997;97:1008-1010.

46. Jeffery RW, French SA, Raether C, Baxter JE. An environmental intervention to increase fruit and salad purchases in a cafeteria. Prev Med. 1994;23:788-792.

47. Horgen KB, Brownell KD. Comparison of price change and health message interventions in promoting healthy food choices. Health Psychol. 2002;21:505-512. 